\title{
Poder e ideologia: o modelo corporativo de gestão por competências em uma indústria multinacional
}

\author{
Cinthia Leticia Ramos* \\ José Henrique de Faria**
}

\section{Resumo}

Sendo as organizaçôes permeadas por relaçóes complexas e contraditórias desencadeadas por mecanismos de poder, ideologia e controle, interessa analisar no presente artigo de que forma estas relaçóes se manifestam no discurso de Gestão por Competência, mediante análise crítica do modelo corporativo implantado em uma Indústria Multinacional, aqui denominada Indústria ALFA, a partir de duas categorias de Análise: Poder e Ideologia. As fontes dos dados empíricos são os documentos institucionais da Indústria ALFA que definem e orientam os procedimentos da Gestão por Competência. A técnica de coleta e análise dos dados será a Análise de Conteúdo segundo a proposta de Bardin e Franco. O enfoque que orienta o problema de pesquisa se dará em torno do sujeito coletivo e sua relação estabelecida com o conjunto de regras e comportamentos ideológicos impostos pela organização o qual se materializa através da submissão, da alienação e da servidão voluntária nas organizaçóes. A base conceitual que dará suporte para sustentação desta investigação levará em consideração uma concepção teórica crítica das formas de poder e controle nas organizaçóes concretas.

Palavras-chave: Gestão por competência. Relaçóes de trabalho. Ideologia e poder.

\footnotetext{
* Mestre em Organizaçóes e Desenvolvimento pelo Centro Universitário Franciscano do Paraná. ** Doutor em Administração pela Universidade de São Paulo. Professor Titular da Pós-Graduação em Administração na Universidade Federal do Paraná (UFPR).
} 


\section{Introdução}

Considerando o fato de que as empresas ocupam lugar de destaque na vida dos indivíduos, é necessário compreender como estes se relacionam com aquelas, em que medida têm sua subjetividade manipulada e como determinados discursos organizacionais atuam não apenas como fator constitutivo da realidade social, mas também como prática ideológica e de poder, contribuindo na construção das identidades sociais e individuais (SIQUEIRA, 2004).

Nesse sentido, pretende-se compreender de que forma a organização objetiva seu poder e sua ideologia mediante o uso de métodos, técnicas e processos embutidos em seu programa de Gestão por Competências, legitimando a adesão, o envolvimento e a concentração do indivíduo na implantação de sua missão e na busca de seus objetivos. Interessa revelar a lógica e o conteúdo do programa de Gestáo por Competências que, segundo Brito (2004), encontra-se alicerçado em uma dinâmica de relaçóes de poder, bem como em uma ideologia materialmente ancorada e amplamente disseminada no âmbito organizacional, reforçando a alienaçáo do trabalhador e possibilitando a subsunção real de caráter subjetivo (FARIA, 2004) do trabalho ao capital.

A base conceitual que dará suporte para sustentação desta investigação levará em consideração a teoria da Economia Política do Poder, caracterizada como uma concepção teórica crítica das formas de poder e controle nas organizaçóes concretas, objetivando esclarecer em que medida as instâncias ocultas, que se operam nos bastidores organizacionais, nas relaçöes subjetivas e no inconsciente individual, manifestam-se na gestão por competências, dando conteúdo às configuraçôes de poder e de controle nas organizaçôes (FARIA, 2004). $\mathrm{O}$ que se deve buscar nos estudos das relaçôes organizacionais são:

As relaçóes internas e externas de poder, manifestadas em suas formas de controle e em sua açáo mediadora de objetivos e desejos, e em sua inserção dinâmica e contraditória na sociedade globalizada, tendo como suporte de análise as relaçóes entre os sujeitos coletivos, no campo do trabalho, da produção, da realizaçáo, do imaginário ou dos afetos, em seus aspectos objetivos e subjetivos, ou seja, as relaçốes de poder. (FARIA, 2007, p. 11). 
Em termos metodológicos, trata-se de um estudo de caso (YIN, 2005), sendo a referência do campo empírico fundada em uma análise documental, na qual os dados secundários se encontram expostos em toda sua dimensão e em que estão explicitados determinados aspectos essenciais para a elaboração da interpretação. Trata-se de uma pesquisa com uma perspectiva analítica de conteúdo, que visa compreender as características do fenômeno organizacional aqui denominado Gestão por Competências.

Tendo em vista que os dados do campo empírico encontram-se registrados em documentos oficiais da Indústria ALFA ${ }^{1}$, optou-se por utilizar a ferramenta denominada "Análise Crítica de Conteúdo" (AC), que considera os aspectos qualitativos que o texto propriamente contém, utilizando-se de duas Categorias de Análise (Poder e Ideologia), de maneira a compreender o que o texto expressa. Nesse sentido, buscou-se um conjunto de elementos que possuem um significado que pudesse ser percebido pelo método e ser transformado em um "indicador" capaz de ser detectado por justaposições e que remetesse às Categorias de Análise (BARDIN, 2002).

Justifica-se a adoçáo da AC neste estudo porque esta nasce com o propósito de superar as interpretaçóes intuitivas dos textos, propondo uma análise objetiva e contextualizada. De início este propósito remeteu a AC à dimensão positivista, em que se valorizavam as medidas, a neutralidade e a quantificação, esta última através de escalas, frequência e correlaçōes. Esta rigidez técnica se mostrou impeditiva para que se alcançasse uma interpretação adequada dos textos, pois as regras e as formas prevaleciam sobre o conteúdo. Os resultados das análises eram parciais, às vezes pouco úteis para o pesquisador e sem significado e sentido. Para Franco (2007, p. 9), isto se deu em decorrência da "confusão conceitual que se estabelece entre método, metodologia e procedimentos metodológicos".

Dessa forma, a AC foi aqui empregada na dimensão da análise qualitativa a partir dos Elementos Constitutivos relativos às Categorias de Análise, permitindo a interpretação dos dados do conteúdo documental. Com base nos resultados das pesquisas que vêm sendo desenvolvidas pelo Grupo de Pesquisa, foram definidas duas Categorias de Análise: Poder e Ideologia. A questão metodológica proposta foi a de encontrar os indicadores (Elementos Constitutivos) destas categorias expressos nos documentos analisados que revelassem a face ideológica e a dinâmica das relaçóes de poder envolvidas no programa de Gestão por Competências. 
A base de referência teórica deste estudo recorreu à concepção da Teoria da Economia Política do Poder (FARIA, 2004) e à abordagem interdisciplinar na qual se enfatizam as contribuiçốes da educação, da psicologia, da psicanálise e da sociologia para o alcance dos objetivos propostos (SIQUEIRA, 2004).

Para efeitos desse estudo, optou-se por trabalhar com o conceito, o conteúdo e a aplicabilidade prática de três competências individuais: trabalho em equipe; orientação por processos e resultados; criatividade e inovação. Também é examinado o perfil de competências associado a todas as funções e cargos da indústria aqui denominada Indústria ALFA. O enfoque que orienta o problema de pesquisa se dá em torno do sujeito trabalhador individual, enquanto unidade fundamental do sujeito coletivo, em sua relação com o conjunto de regras e comportamentos exigidos pela organização, mediante a implantação do modelo de Gestão por Competências no âmbito das relaçóes de trabalho. Desse modo, serão tratados, na sequência, a concepção de gestão por competência e sua orientação epistemológica no campo da educação; as relaçôes de trabalho e a gestão por competência, com a finalidade de contextualizar o momento histórico-social em que este tema se apresenta; as relações de poder e a gestão por competência, com o objetivo de fundamentar a análise do programa; a ideologia como discurso de poder e a gestão por competência, com o mesmo objetivo anterior. Com base nessas definiçóes, a análise do conteúdo dos programas permitiu apontar os indicadores (elementos constitutivos) das Categorias de Análise no programa da Indústria ALFA, que são apresentados em suas formas relacionais com o que a empresa denomina de escala de proficiência (Quadros 1, 2, 3 e 4).

\section{A origem epistêmica da gestão por competências}

Como se verá adiante, a literatura sobre gestão por competências é bastante usual nos estudos organizacionais. No entanto, tal literatura não sinaliza sua origem epistêmica no plano da educação, onde é necessário buscála. Em geral, competência é considerada como inteligência prática tendo em vista situaçôes que se apoiam sobre os conhecimentos adquiridos pelos sujeitos, transformando-os na medida em que aumenta a complexidade das situaçóes vividas, de maneira que tais conhecimentos apenas adquirem o status de competência quando comunicados e utilizados (ZARIFIAN, 2001). Trata-se, assim, de uma concepção que se baseia na ideia do comportamento adaptativo 
do sujeito ao meio, uma forma distorcida do construtivismo piagetiano. Embora Piaget tenha se dedicado ao desenvolvimento moral da criança, sua teoria tem sido utilizada no desenvolvimento de competências em adultos no âmbito do trabalho.

Na perspectiva de Piaget $(1975,1976)$, todo o sujeito possui modos de reação passíveis de serem generalizados de uma ação a outra, que o autor chama de "esquemas". Estes modos constituem a principal fonte dos conceitos e possibilitam a adaptação do sujeito ao meio, a qual se dá através de seus mecanismos constituintes: a assimilação (ação do sujeito sobre o objeto), a acomodação (ação do objeto sobre o sujeito) e a equilibração (processo autorregulador de enfrentamento de conflitos e desequilíbrios). Desde o início as estruturas mentais alicerçam tanto a formação quanto o funcionamento dos esquemas. Assim, as estruturas são modificadas pelos novos esquemas, ou seja, reestruturam-se em um movimento permanente e dinâmico, no qual contradiçóes e paradoxos ocupam seus lugares, pois não se trata de um percurso linear.

Para Piaget $(1975,1976)$, desde seu nascimento o sujeito possui uma forma de funcionar, dada por sua condição humana. Trata-se de uma "herança genética”, ou seja, em seu início, na constituiçăo do indivíduo, seu padrão de funcionamento, descrito pela Neurobiologia dos Processos Mentais e do Comportamento como sistemas neurais organizados (BUSS, 1999; DAMÁSIO, 1999), obedece princípios gerais e a estruturas próprias do mapa genético, constituindo os primeiros atributos e capacidades individuais. Esta forma, portanto, é o ponto de partida da constituição das estruturas mentais por um processo organizado de adaptação, de forma que o sujeito, ao longo de seu próprio desenvolvimento, através das relaçóes sociais, (i) assimila o que lhe é fornecido pela e nas interaçôes (age sobre o objeto); (ii) acomoda este conhecimento (ajeita a ação do objeto sobre suas estruturas); (iii) percebe, a certa altura, que o objeto resiste a ser apanhado por seu esquema, o que o coloca em conflito, desequilibrando-o; (iv) busca a equilibraçáo em novo esquema; (v) torna a assimilar e acomodar em um movimento contínuo; (vi) experimenta um novo desequilíbrio o qual renova os esquemas; (vii) estabelece relaçóes entre os mesmos, ampliando e aprimorando cada vez mais as estruturas da inteligência. Evidentemente, estas operaçóes não se dão desta forma esquemática, pois se trata de um processo complexo.

Essa concepção piagetiana ensina a dinâmica do relacionamento do sujeito com o conhecimento, porém, como se trata de uma epistemologia aplicada às 
crianças, jovens e adultos, parte do princípio segundo o qual o sujeito age sobre o objeto antes de o objeto "conversar" com o sujeito. Todavia, no que se refere à questão do conhecimento no campo do trabalho, o objeto que tem primazia sobre o pensamento decorre de uma definiçấo organizacional do que seja a competência requerida e não da condição do sujeito diante do objeto de trabalho. A forma como o pensamento se organiza em suas relaçốes sociais no campo organizacional é, assim, constantemente renovada pelas exigências do mundo competitivo, de maneira que ao mesmo tempo em que se formulam novas concepçôes e conceitos, também se geram informaçóes e processos de controle e compartilhamento de dados fornecidos tanto pela realidade das relaçóes de trabalho como pelo simbólico e pelo ideológico organizacional, constituindo, dessa maneira, o fundamento da atitude manifesta e exibida e da sua compreensão.

Gradativa, dinâmica e contraditoriamente, o desenvolvimento do sujeito depende de sua condição de internalizar e se apropriar em suas estruturas racionais e afetivas das interaçóes que é capaz de formular conscientemente a partir das relaçóes de poder e da ideologia do sistema de capital presentes na gestấo das organizaçóes. Contudo, a formulaçáo racional e objetiva do conhecimento sobre o objeto pela consciência náo tem como evitar o que se encontra inscrito no inconsciente. A consciência tampouco pode ser resultado ou reflexo da realidade objetiva.

O desenvolvimento das "estruturas" racionais e afetivas se dá sempre em processos no quais a razão e o sentimento ampliam e flexibilizam seu escopo. Tanto a formação como o desenvolvimento da consciência e do afeto, de acordo com a proposta piagetiana, estáo condicionadas à maturação orgânica do sujeito (nervosa, endócrina), à transmissão social (convençôes, valores, códigos, afetos, costumes), à experiência (física e lógico-matemática) e à "equilibração" (dinâmica e dialética). Este processo não está presente apenas no aparato consciente-racional, permanecendo escondido no inconsciente. Isto porque, para Piaget (1973), não existem dois domínios, o do consciente e do inconsciente, separados por uma fronteira, mas um único, do qual, mesmo nos estados mais lúcidos, só se percebe uma pequena parte, a qual escapa quase que totalmente quando já não se a controla de perto.

Assim, o autor desenvolveu uma teoria da cognição (ou do desenvolvimento do conhecimento), na qual propôs a existência de quatro estágios: sensóriomotor, pré-operacional (pré-operatório), operatório concreto e operatório formal. Para Piaget (1973), a capacidade cognitiva se desenvolve e náo vem 
pronta, sugerindo que o conhecimento não nasce no sujeito, nem no objeto, mas origina-se da interação sujeito-objeto.

Isto torna a análise do conhecimento, que o sujeito possui e que expressa, e das experiências que acumula, uma tarefa que exige a negação da ideia de totalidade enquanto conhecimento absoluto, ou seja, o pensamento jamais consegue se apropriar do real de maneira total e absoluta, mas necessariamente relativa e provisória. De acordo com a proposição piagetiana, existem dois tipos básicos de experiência a que os sujeitos são submetidos:

- A experiência física: refere-se à interação do sujeito com o real a partir das propriedades do real. Interação na medida em que o sujeito só pode se relacionar com o real enquanto uma açấo própria que tem por suporte os esquemas constituintes da estrutura. Aqui, com seus esquemas, o sujeito realiza uma abstração do real de acordo com as propriedades deste e com os esquemas de apreensão daquele;

- A experiência lógico-matemática: refere-se a uma abstração decorrente da ação do sujeito sobre o real, ou seja, decorrente das propriedades da açâo do sujeito (BATTRO, 1978).

Em ambos os casos, o sujeito é sempre e necessariamente ativo na relação com o real. Dito de outra forma, ação e pensamento constituem a percepção inteligente, constituem uma percepçáo do objeto pelo pensamento na qual a relação do sujeito com o real não está configurada em uma simultaneidade, pois é preciso que o sujeito se aproprie do real na forma de esquemas de interação e interpretação. A teoria da epistemologia genética de Piaget, desenvolvida no campo da educação, ajuda a compreender como esta orientaçáo foi apropriada pelas organizaçóes, fora do contexto pretendido por Piaget, e utilizada para o desenvolvimento de competências e sua gestáo ${ }^{2}$. A concepçáo de que o conhecimento se desenvolve e que se baseia na interaçáo sujeito-objeto é a base epistêmica dos programas de gestão por competências.

\section{Relações de trabalho e gestão por competências na sociedade contemporânea}

\section{Relaçôes de Trabalho}

Batista e Clark (2009) sugerem que as mudanças ocorridas no mundo do trabalho têm afetado direta e intensamente a classe trabalhadora devido às crescentes, 
profundas e diversificadas formas de trabalho precarizados, informais, destituídos de direitos, sem sentido e brutal. Para justificar o desemprego, a miséria, os trabalhos precários e terceirizados são criados novos conceitos. Na perspectiva da ideologia do sistema de capital (MÉSZÁROS, 2002), a responsabilidade desta situaçáo social é transferida ao próprio trabalhador por não ter se qualificado e se preparado para as mudanças que estão ocorrendo, o que faz com que seja considerado não apto e não empregável, pois não atende aos requisitos exigidos para o trabalho.

Este discurso ideológico da classe dominante tem como estratégia desviar a atenção ou mesmo fazer crer para a classe trabalhadora, que possibilidades existem, mas precisa-se preparar para elas, que se estudar e 'lutar na vida' o sujeito conseguirá o 'sucesso' na sociedade do consumo. (BATISTA; CLARK, 2009, p. 11-12).

Nessa mesma linha de argumentaçáo, Pagès et al. (1987, p. 35) mostram que a organização "hipermoderna" passou por grandes modificaçōes, alterando profundamente as condiçóes de luta social, tais como: "a intelectualização das tarefas, o papel cada vez maior das ciências e das técnicas em todos os níveis da produção, a maior divisão técnica do trabalho e a interdependência das tarefas, a mudança e a renovação constantes". Isso demanda:

Trabalhadores instruídos capazes de compreender os princípios de sua ação e não apenas de cumprir tarefas rotineiras, capazes de iniciativas, não só aceitando, mas desejando a mudança, aderindo voluntariamente a seu trabalho e interessando-se por ele, capazes e desejosos de cooperar com os outros, náo apenas com os colegas permanentes, como nas antigas oficinas, mas de adaptação rápida a equipes mutantes, e às força-tarefa provisórias. (PAGÉS et al., 1987, p. 35).

Ainda segundo Pagès et al. (1987, p. 37), "o homem da organização liberta-se da tutela estrita e mesquinha do chefe [com a qual] é obrigado a se identificar para aprender a viver, para cair sob uma tutela muito mais obscura, ameaçadora e insidiosa de uma entidade impessoal que penetra na sua vida e na sua alma, de ponta a ponta”. Para Dejours (2001), há um processo em curso no qual se pretende: 
[...] fazer acreditar que o sofrimento do trabalho foi bastante atenuado ou mesmo completamente eliminado pela mecanização e a robotização, que teriam abolido as obrigaçóes mecânicas, as tarefas de manutenção e a relação direta com a matéria que caracterizam as atividades industriais. (DEJOURS, 2001, p.27).

Assim, para Dejours (2001), não é mais o medo de acidentes que se impóe soberanamente, pois por trás da vitrina está: o medo da incompetência; a pressão para trabalhar mal resultante das relaçóes com colegas e dos obstáculos criados para estabelecer um padrão de desempenho mais baixo; a falta de esperança de reconhecimento, componente decisivo na dinâmica da mobilização subjetiva da inteligência e da personalidade no trabalho; o sofrimento e a defesa para suportar as pressóes.

Nesse mesmo sentido, Gaulejac (2007) critica o caráter ideológico da gestão, revelando que por detrás dos instrumentos, procedimentos, planos de gestão e de comunicação há um sistema de crenças e de visão de mundo unilateral que legitima os mecanismos de poder organizacional, fortalecendo a ilusão de onipotência, neutralidade das técnicas e modelação de condutas humanas, bem como a dominação de um sistema econômico que busca incessantemente o lucro. Para Gaulejac (2007), é possível exercer uma "pseudo liberdade" dentro das organizaçôes, desde que o sujeito potencialize seus esforços, energia e criatividade para os resultados gerenciais. O discurso de excelência, revestido por uma prática excepcional para obtenção de resultados, induz o indivíduo a assumir um projeto de eterna superação, com objetivos "fora do comum", metas inalcançáveis em direção a uma corrida de ideal mítico inacessível.

Esses estudos sugerem que o controle ideológico, decorrente do desenvolvimento da relação gerencialista, é uma forma de poder difícil de ser percebido pelos indivíduos, pois os conflitos se colocam no nível psicológico em termos de insegurança, sofrimento psíquico, esgotamento profissional, perturbações psicossomáticas, depressões nervosas, entre outras. É também de difícil qualquer contestação, porque, ao operar na "interioridade do indivíduo", a unidade organizacional faz com que o mesmo conteste a si próprio, sendo, como indica Gaulejac (2007), uma espécie de "alienação à segunda potência”, resultado da fusão entre o ego e o ideal de ego, incitado pelo gerencialismo. 
É neste sentido que a prática de Gestão por Competências legitima-se como a capacidade desenvolvida pelas organizações de mapear na sociedade, trazer para a organização, distribuir, criar, recompensar e reter conhecimento relacionado à sua competência essencial. Isso implica direcionar toda a gestão da empresa, a gestão do trabalho e, consequentemente. o processo de educação dos trabalhadores para a consecução da sua missão organizacional (BRITO, 2008).

Para analisar criticamente os elementos centrais da prática de Gestão por Competências (de que ponto de vista ela foi definida, com que finalidade foi implantada e que interesse representa), torna-se relevante entender seu conceito, sob o ponto de vista gerencialista, bem como sua aplicabilidade prática e estratégica no contexto de Gestáo de Pessoas. Para os objetivos do presente estudo não se trata de discutir os diversos conceitos de Gestão por Competência, mas enfatizar alguns pontos relevantes propostos na literatura sobre o tema, visando à construção do referencial conceitual que dará sustentaçáo aos argumentos que se seguirão.

\section{Gestão por competências na sociedade contemporânea}

O conceito de competência, no âmbito da gestão de pessoas, surge em 1973 com a publicação do artigo "Testing for Competence rather than Intelligence", escrito por McClelland (1973). McClelland (1971) discute os testes para avaliar as competências, tendo por base os seus conceitos de competência e de White (1959),, indicando que competência é uma característica subjacente a uma pessoa, casualmente relacionada com desempenho superior na realizaçáo de uma tarefa ou em determinada situação. A partir desse conceito, passa-se a diferenciar competência de aptidão, sendo esta última entendida como o talento natural (que pode vir a ser aprimorado), as habilidades ou a demonstração de um talento particular na prática e seus conhecimentos, ou seja, o que as pessoas precisam saber para desempenhar uma tarefa (MIRABILE, 1997). Embora McClelland não se refira explicitamente à teoria piagetiana, à época com grande repercussão nas escolas e nos cursos de psicologia nos Estados Unidos, sua concepção é a de que a competência se pode medir e desenvolver, sendo que tal desenvolvimento está relacionado com a tarefa (interação sujeito-objeto).

Prahalad e Hamel (1996, p. 233) afirmam que uma competência é um "conjunto de habilidades e tecnologias, e não uma única habilidade e tecnologias isoladas, que permitem a uma empresa oferecer determinado 
benefício". A questão principal diz respeito à possibilidade de combinação das várias competências que uma empresa pode conseguir para desenhar, produzir e distribuir produtos e serviços aos clientes no mercado. Competência seria, assim, a capacidade de combinar, misturar e integrar recursos em produtos e serviços.

Enquanto que para Fleury e Fleury (2001) a competência náo se limita a um estoque de conhecimentos teóricos e empíricos detido pelo indivíduo, nem se encontra encapsulada na tarefa. Para Zarifian (2001), a competência é a inteligência prática para situaçóes que se apoiam sobre os conhecimentos adquiridos e os transformam com tanto mais força quanto mais aumenta a complexidade das situaçóes, ou seja, os conhecimentos e o know how só terão status de competência na medida em que forem comunicados e utilizados. Para Fleury e Fleury (2001), a noção de competência aparece associada a verbos como: saber agir, mobilizar recursos, integrar saberes múltiplos e complexos, saber aprender, saber engajar-se, assumir responsabilidades e ter visão estratégica. A partir desse entendimento Fleury e Fleury (2001, p. 188) definem a competência como: "um saber agir responsável e reconhecido, que implica mobilizar, integrar, transferir conhecimentos, recursos e habilidades, que agreguem valor econômico à organização e valor social ao individuo".

A partir dos conceitos acima expostos e segundo Boam e Sparrow (1992), a competência é um conjunto de padrões de comportamento que o trabalhador necessita para obter um bom desempenho no trabalho. Essa definição sugere que as competências são repertórios de comportamentos e capacitaçóes que certos indivíduos ou organizaçóes dominam melhor que outros, tornando-os eficazes em uma determinada situação.

Para Faria e Leal (2007), a noção de competências vinculada à gestão de recursos humanos desloca-se do foco da tarefa para a noção de suporte à estratégia organizacional. Isso porque o trabalho já não representa um conjunto de habilidades e requisitos definidos a partir do desenho do cargo, mas sim de uma nova dinâmica vinculada à complexidade e flexibilidade das relaçôes de trabalho impostas pelas organizaçóes contemporâneas. Para os autores, a competência só adquire status quando é útil em um contexto produtivo, sendo que a estratégia é quem determina essa utilidade (FARIA; LEAL, 2007).

Nesse sentido, Faria e Leal (2007) argumentam que a competência não é uma medida absoluta, mas relativa a um desempenho melhor em relação a um pior. Essa ideia encontra-se profundamente relacionada à noção de vantagem competitiva. Para esses autores, a expressão "competências" designa, no âmbito da gestão capitalista, 
um parâmetro a ser seguido de comportamento humano e organizacional e admite implicitamente o sentido político e ideológico da competição como parâmetro de excelência, sentido esse que perpassa pelo individualismo e, consequentemente, pela desmobilização da luta coletiva dos interesses dos trabalhadores (FARIA; LEAL, 2007). Portanto, como pode ser observado,

O programa de competências provoca, entre os trabalhadores, a perseguição de um "ideal de perfeição", desenvolvendo processos de identificaçấo e de introjeção dos valores organizacionais pelos indivíduos. Desta forma, ao valorizar as competências, a organização induz o indivíduo a perseguir objetivos e regras que ela dita, mas que acabam por se tornar vitais para o seu próprio funcionamento psicológico, de maneira que este possa oferecer àquela uma extrema dedicação. (FARIA; LEAL, 2007, p. 165).

\section{Relações de poder e gestão por competências}

Para compreender o programa de gestáo de competência como uma forma de exercício do poder, parte-se do conceito de que o poder é um atributo coletivo, mais propriamente, uma capacidade coletiva de "definir e realizar interesses objetivos específicos, mesmo contra a resistência ao exercício desta capacidade e independentemente do nível estrutural em que tal capacidade esteja principalmente fundamentada" (FARIA, 2004, p. 141). O poder, em si mesmo, é uma abstraçáo e seu sentido somente pode ser compreendido em sua concretização, em seu exercício, em suas práticas, ou seja, nas relaçóes de poder. Assim, para que os interesses dominantes se realizem, torna-se necessário colocá-los em prática. Dessa forma, a gestão por competências é uma estratégia de realização dos interesses da organização a partir da definição de seus objetivos, os quais operam o sentido do controle, nesse caso, do desempenho dos empregados. Este é um ponto de vista que, segundo Faria e Leal (2007), náo tem sido abordado nas pesquisas sobre o tema em Administração.

Faria e Leal (2007, p. 165) entendem que o discurso da gestáo por competências,

[...] atua como instrumento da hegemonia capitalista configurando um padrão de comportamento que 'hierarquiza' os trabalhadores segundo o seu 'talento', 
recompensando-os ou punindo-os segundo os mesmos, estabelecendo as condiçôes de desempenho e a perseguiçẫo de um 'ideal de perfeição', bem como desenvolvendo processos de identificação e de introjeção dos valores organizacionais.

Nesse sentido, tal programa constitui-se em uma ideologia do poder da organização.

Para Brito (2008, p. 219):

As exigências, cada vez maiores, das empresas levam o empregado a ter de estar continuamente buscando, criando e disseminando conhecimentos para a empresa, ao mesmo tempo em que o conhecimento construído fica retido na empresa mesmo com a demissão do empregado. Os produtos do trabalho: o conhecimento explícito não pertence ao trabalhador e está disponibilizado nas redes tecnológicas da empresa e o conhecimento tácito é assimilado na prática por outros trabalhadores, não garantindo mais o emprego de quem o desenvolveu ao longo da experiência. Ao mesmo tempo em que o trabalhador deve desenvolver, nas organizaçôes de aprendizagem, o seu potencial, o aprendizado em grupo, a visão compartilhada e o raciocínio sistêmico, ele precisa abrir mão de uma visão pessoal de mundo consolidada ao longo de sua existência, mudando continuamente seus quadros mentais, não como um processo integral de desenvolvimento, mas negando a própria identidade e referências para se adequar às necessidades do capital.

Lydia Brito (2008) argumenta que os processos de educação corporativa e de gestáo por competência mobilizam os aspectos subjetivos do trabalho envolvendo a cultura, os valores, o coração e a mente dos funcionários num processo de aprendizado contínuo capaz de liberar a força criativa de cada um, projetada para atingir os resultados desejados pela organização, ou seja, para defender os interesses do capital, manter sua competitividade no mercado e garantir seu lucro e a sua sobrevivência, ao concentrar a inteligência, a emoçáo e a energia dos empregados nas estratégias empresariais. Seguindo esta lógica, a 
autora sugere que a grande diferença entre a forma de compartilhamento natural do conhecimento e as novas formas de compartilhamento do conhecimento, promovida pelas organizaçóes, é:

O gerenciamento, manipulação e controle rigoroso do processo de aprendizagem a partir unicamente dos interesses do capital, fato que significa uma mudança sem precedentes na forma de gestão e educação de pessoas para o trabalho nas organizaçóes ao interferir direta e claramente na cultura organizacional e ao criar propositadamente um imaginário enganador na organização. (BRITO, 2008, p. 207).

Segundo Siqueira (2004), o indivíduo será levado a desenvolver uma atitude de super-herói, de uma pessoa bem acima da média, um trabalhador polivalente, atualizado e imbuído do "espírito" da organização. O sucesso é a palavra de ordem e obter o triunfo passa a ser necessidade do indivíduo, que deve se dedicar inteiramente a tal sucesso. Os indivíduos devem se inserir nesta lógica sendo competitivos, pois se "perderem o jogo", estarão "relegados ao limbo". Para o autor, deve-se questionar, entretanto, não a existência de controles ou de estrutura organizacional, mas sim, o modo como a empresa utiliza desses mecanismos que, em determinadas situaçóes, acabam por prender a criatividade e a singularidade do indivíduo.

Todos os argumentos relacionados acima indicam que o poder atua nas mais diversas frentes e nos mais variados modos, buscando sempre reconduzir o indivíduo, por meio das regras, aos caminhos (interesses) definidos pela empresa. Tal é a direção que o trabalhador deve percorrer. Essas direçóes (definir os interesses) e estratégias de exercício de poder (realizar os interesses) permitem analisar suas manifestaçóes no discurso de Gestáo por Competência, pois esta é uma política organizacional que preenche os requisitos do envolvimento, da entrega, do comprometimento e da introjeçáo de valores. Nesse sentido, é oportuno questionar sob qual ponto de vista o programa de Gestáo por Competências é definido, com que finalidade o mesmo é implantado e que interesse representa. Nessa linha de argumentação, entende-se que este programa se constitui em uma forma de controle sobre o aprendizado e, conforme afirma Brito (2008), constitui-se, em sua essência, na forma mais sofisticada de apropriação e alienação do trabalho, devido ao fato de que, além 
de se apropriar dos movimentos, tempo e ritmo do trabalhador, também se apropria da teleologia, do conhecimento tácito (que muitas vezes o trabalhador não se dá conta que possui), do desejo, do abstrato, das formas de interação e da criatividade coletiva.

\section{A ideologia como discurso de poder}

O conceito de ideologia possui muitas vertentes (CENTRE, 1980). Uma das maneiras pela qual se pode conceber a ideologia é que ela é um reflexo invertido, mutilado, deformado do real, na medida em que significa um conjunto abstrato de ideias, representaçôes e valores de determinada sociedade. Trata-se de uma concepção abstrata no sentido de designar todo e qualquer conjunto de ideias que pretenda explicar fatos observáveis sem vincular essa explicação às condiçôes sociais, históricas e concretas em que tais fatos foram produzidos. Apesar da desvinculação, essas ideias são transmitidas e absorvidas como se fossem reais (FRANCO, 2004)

Para Mészáros (2004, p. 65):

A ideologia não é ilusão nem superstição religiosa de indivíduos mal orientados, mas uma forma específica de consciência social, materialmente ancorada e sustentada. Como tal não pode ser superada nas sociedades de classe. Sua persistência se deve ao fato de ela ser constituída objetivamente (e constantemente reconstituída) como consciência prática inevitável das sociedades de classe, relacionada com a articulação de conjuntos de valores e estratégias rivais que tentam controlar o metabolismo social em todos os seus principais aspectos.

Segundo o autor, o conflito mais fundamental na arena social refere-se à própria estrutura social que proporciona o quadro regulador das práticas produtivas e distributivas de qualquer sociedade específica, cujo objetivo é manter ou, ao contrário, negar o modo dominante de controle sobre o metabolismo social dentro dos limites das relações de produção estabelecidas. Tal conflito encontra suas manifestaçôes necessárias nas "formas ideológicas (orientadas para prática) em que os homens se tornam conscientes desse conflito e o resolvem pela luta" (MÉSZÁROS, 2004, p. 65), ou seja, as diferentes formas 
ideológicas de consciência social têm implicações práticas de longo alcance em todas as suas variedades, independentemente de sua vinculação sociopolítica a posiçôes progressistas ou conservadoras.

Nesse sentido, náo se pode reduzir o conceito de ideologia como simplesmente uma "falsa consciência". O que define a ideologia como ideologia não é seu suposto desafio à "razão" ou seu afastamento das regras preconcebidas de um "discurso científico" imaginário, mas sim sua situação real - materialmente fundamentada - em um determinado tipo de sociedade. As funções complexas precisam focalizar a atenção nas exigências práticas vitais do sistema de reprodução (MÉSZÁROS, 2004).

Tomando como referência o discurso ideológico como veículo da manifestação expressa do poder, seja para convencer, seja para impor ou para estabelecer acordos (FARIA, 2004), pode-se verificar que de uma forma especial a gestão por competências incorpora um conjunto de conteúdos de ordem prática, política e ideológica, historicamente relacionado com os interesses econômicos do capital. Essa relação entre poder e ideologia, em que se apresenta como uma das formas discursivas daquele, precisa ser desvendada para que se possam compreender as relaçóes concretas.

Como já notaram Marx e Engels (2007) em sua famosa crítica à ideologia alemã e Castoriadis (1982) em seu clássico estudo sobre a instituição imaginária da sociedade, a ideologia produz seu próprio esquema de interpretação, de dissimulação, de justificação, de divulgação e de renovação. Para examinar as relaçôes de poder e o esquema de interpretação ideológica que se encontra expresso em um programa de gestão por competência (enquanto um conjunto de saberes requerido pela organização) de forma a se conferir um sentido aceitável ao par competência-ideologia, é necessário observar, inclusive na perspectiva hermenêutica de Ricouer (1990, p. 92; 95, grifo do autor), que: (i) "todo o saber objetivante" sobre a "posição na sociedade, numa classe social, numa tradição cultural, numa história, é precedido por uma relação de pertença que jamais poderemos refletir inteiramente"; (ii) se o saber pode se distanciar da ideologia, esta é sempre um código de interpretação.

A investigação deve partir de bases reais e não da imaginação que se tem sobre a realidade.

Não se parte daquilo que os homens dizem, imaginam ou representam, e tampouco dos homens pensados, 
imaginados e representados para, a partir daí, chegar aos homens em carne e osso; parte-se dos homens realmente ativos e, a partir de seu processo de vida real, expóe-se também o desenvolvimento dos reflexos ideológicos e dos ecos desse processo de vida. [...] Os homens, ao desenvolverem sua produção material e seu intercâmbio material, transformam também, com esta sua realidade, seu pensar e os produtos de seu pensar. (MARX; ENGELS, 2007, p. 37).

\section{Poder e ideologia em um programa de gestão por competências}

Mediante análise crítica do programa de Gestão por Competências da Indústria ALFA, pretende-se responder a três questōes fundamentais do mesmo: (i) sob qual ponto de vista o programa foi definido? (ii) Com que finalidade o programa foi implantado? (iii) Que interesses o programa representa? Com estas questôes objetiva-se indicar a ideologia e as relaçóes de poder expressas e contidas no programa.

Para melhor responder as questóes é necessário aditar ainda quatro questôes complementares: qual a concepção do processo educativo (ideologia) que está por trás do conteúdo e da prática construída pela Indústria ALFA? Que tipo de conhecimento (ideologia) é requerido e disponibilizado pela empresa para o trabalhador? Como a empresa se apropria (relação de poder) do conhecimento do trabalhador? Em que medida o modelo contribui ou não para a intensificação do processo de alienação (relação de poder) e, consequentemente, para a precarização das condiçôes e relaçóes de trabalho?

Ao analisar o conteúdo do programa de Gestão de Competências expresso no documento produzido pela Indústria ALFA adotando procedimento analítico sugerido por Bardin (2002) e Franco (2007), foi possível destacar sete pontos fundamentais, descritos a seguir. Os três primeiros são relativos à categoria relaçóes de poder, os três seguintes relacionados à disseminação da ideologia da empresa e o último relativo a ambas as categorias ao mesmo tempo. Os seis primeiros pontos encontram-se resumidamente expressos nos Quadros 2, 3 e 4 . O sétimo ponto encontra-se expresso no Quadro 5. 
1. O Programa de Gestão por Competências é o instrumento definido pela indústria ALFA para desdobrar suas estratégias, materializando-se em um conjunto de comportamentos estruturados e diferenciados que facilitam a execução e integração dos processos: orientando a gestão dos empregados com um estilo comum; explicitando quais os comportamentos dos empregados esperados pela companhia; possibilitando o alinhamento das pessoas às necessidades do negócio (relação de poder).

2. A Gerência de Recursos Humanos, responsável por implantar o programa e garantir sua aplicabilidade e aderência com as diretrizes corporativas, aplica o programa nos seguintes processos: educaçâo corporativa; aprendizagem organizacional; gestâo do conhecimento; dimensionamento de equipes; recrutamento e seleção; gestão de desempenho; alocação, mobilidade e sucessão (relação de poder).

3. Cada competência individual é composta por: (i) título: nome da competência; definição e descrição detalhada do significado da competência que uniformiza seu entendimento; (ii) atributos: conjunto de Conhecimentos, Habilidades e Atitudes (CHA); (iii) escala de proficiência: representa uma regra para definir a expectativa requerida pela ALFA, bem como para avaliar o nivel em que o empregado se encontra. Essa escala evolutiva é composta por quatro niveis ( $A, B, C e D)$, cada um com sua definição. O nível A é o de menor complexidade e o $\mathrm{D}$ o de maior complexidade (relação de poder).

4. O Dicionário de Competências descreve de forma conceitual e prática as competências organizacionais e as competências individuais corporativas, sendo seu principal objetivo prover os conceitos e elementos que as compóem, assim como orientar os processos de gestão de pessoas garantindo a identidade organizacional além das fronteiras geográficas (ideologia).

5. O programa identifica oito competências organizacionais: orientação para o mercado, gestão empresarial, inovação e tecnologia para os negócios, gestão de pessoas, gestão da cadeia de suprimentos, gestão de processos, gestão de portfólio, programa e projetos, responsabilidade social e ambiental. Cada uma delas possui um detalhamento dessa descrição, intensificando o alinhamento às estratégias da ALFA (ideologia).

6. Além das competências organizacionais, foram identificadas nove competências individuais: trabalho em equipe, iniciativa, liderança de pessods, atuação estratégica, orientação para processos e resultados, criatividade e inovação, aprendizagem e compartilhamento do conhecimento, foco no cliente, capacidade 
de decisão. Tais competências devem estar presentes em todos os empregados garantindo a identidade corporativa (ideologia).

Como nem sempre todos os empregados atendem plenamente o nível requerido para as competências, a empresa definiu uma escala de avaliação em que o empregado é posicionado. Essa escala vai desde "não demonstrada", quando o avaliado não apresenta nenhum traço do nível requerido para a competência, até "supera o nível requerido". Esta escala está expressa nos Quadros 1, 2 e 3. Nesses quadros encontram-se ao mesmo tempo os seis pontos mencionados, pois no plano concreto as categorias não se apresentam separadas. A apresentação do programa nos Quadros, adiante, pretende apenas reproduzir sinteticamente a lógica explícita do programa da Indústria ALFA, que será analisada em cada um dos componentes a partir das Categorias de Análise.

No Quadro 1, em que se explicita a avaliação da escala de proficiência no âmbito do trabalho em equipe, pode-se observar a contradição entre a concepção de que as competências individuais são consideradas no âmbito do trabalho em equipe e a definição deste trabalho. De fato, o trabalho em equipe é definido como a capacidade de trabalhar cooperativamente de forma a integrar os interesses individuais aos do grupo, tendo em vista o alcance de um objetivo comum e a busca de resultados para o negócio. A integração dos interesses é regida pelos resultados para o negócio e pelo objetivo comum definido pela empresa. Nota-se, aqui, que o poder (capacidade definir e realizar de interesses) é aquele comandado pela Indústria ALFA e não o definido pelo grupo a partir de um trabalho cooperativo. Nesse aspecto, as competências individuais são as de intervenção, atuação, facilitação e constituição de referência no âmbito do grupo para garantir o projeto da Indústria ALFA. As competências não são propriamente individuais. São competências requeridas do indivíduo pela Indústria ALFA. Compartilhar experiências, agregar qualidade, integrar pessoas em um ambiente produtivo e cooperativo e estimular a equipe à obtenção e superaçáo de resultados são indicadores de como o discurso ideológico da Indústria ALFA é disseminado no programa.

Outra contradição relevante identificada no discurso de trabalho em equipe é a competitividade que se estabelece, de forma velada, entre os pares. Ao mesmo tempo em que o discurso estimula a necessidade de cooperação, de integração e participação coletiva, o trabalhador é avaliado individualmente em cada competência. Caso o mesmo não alcance as metas estabelecidas, terá "gap's de desempenho" em sua proficiência requerida, impactando diretamente 
na progressão da carreira e evolução salarial. Em outras palavras, por trás do discurso coletivo há um estímulo à competitividade individual, bem como um controle para que a subjetividade do trabalhador seja utilizada para interesses da empresa, o que influi, consequentemente, na redução de sua consciência crítica e na desmobilização para lutas por melhorias de direitos e condições de trabalho.

Outro ponto relevante no discurso organizacional é o estímulo à participação individual como atributo fundamental para se trabalhar em equipe. Segundo PAGÈS (1987), esta participação está relacionada, entre outras coisas, com a flexibilidade organizacional, em que o controle ideológico com aspecto flexível vai admitir a diversidade e dar certa autonomia ao sujeito do trabalho. Contudo, tanto a autonomia quanto a participação são vigiadas e vão até o ponto em que não comprometam as diretrizes e normas organizacionais, que não coloquem em risco a estrutura de poder e o discurso ideológico produzido pela organização.

Quadro 1 - Escala de proficiência para as Competências Individuais Corporativas: trabalho em equipe

\begin{tabular}{|c|c|c|c|c|c|c|c|c|}
\hline \multicolumn{2}{|c|}{$\begin{array}{l}\text { Competências Individu- } \\
\text { ais Corporativas }\end{array}$} & \multicolumn{7}{|c|}{$\begin{array}{l}\text { ESCALA DE PROFICIÊNCIA } \\
\text { Avaliação }\end{array}$} \\
\hline \multicolumn{2}{|c|}{ Trabalho em Equipe } & \multirow{3}{*}{$\begin{array}{l}\text { Não me } \\
\text { sinto apto } \\
\text { a avaliar }\end{array}$} & \multirow{3}{*}{$\begin{array}{l}\text { Não } \\
\text { Demons- } \\
\text { trada }\end{array}$} & \multicolumn{3}{|c|}{$\begin{array}{l}\text { Em desenvolvi- } \\
\text { mento }\end{array}$} & \multirow[b]{2}{*}{$\begin{array}{l}\text { Apli- } \\
\text { cação } \\
\text { integral }\end{array}$} & \multirow[b]{2}{*}{$\begin{array}{l}\text { Supera } \\
\text { nível } \\
\text { requerido }\end{array}$} \\
\hline \multirow{2}{*}{\multicolumn{2}{|c|}{$\begin{array}{l}\text { Capacidade de traba- } \\
\text { lhar cooperativamente, } \\
\text { integrando interesses } \\
\text { individuais aos do } \\
\text { grupo, para alcance de } \\
\text { um objetivo comum, na } \\
\text { busca de resultados para } \\
\text { o negócio, considerando } \\
\text { as características pessoais, } \\
\text { culturais e profissionais. }\end{array}$}} & & & $\begin{array}{l}\text { Inicia- } \\
\text { ção }\end{array}$ & $\begin{array}{l}\text { Apli } \\
\text { inter } \\
\text { diari }\end{array}$ & & & \\
\hline & & & & 1 & 22 & 33 & 4 & 5 \\
\hline A & $\begin{array}{l}\text { Atua realizando } \\
\text { algumas interven- } \\
\text { çóes na equipe, } \\
\text { compartilhando } \\
\text { experiências. }\end{array}$ & & & & & & & \\
\hline
\end{tabular}




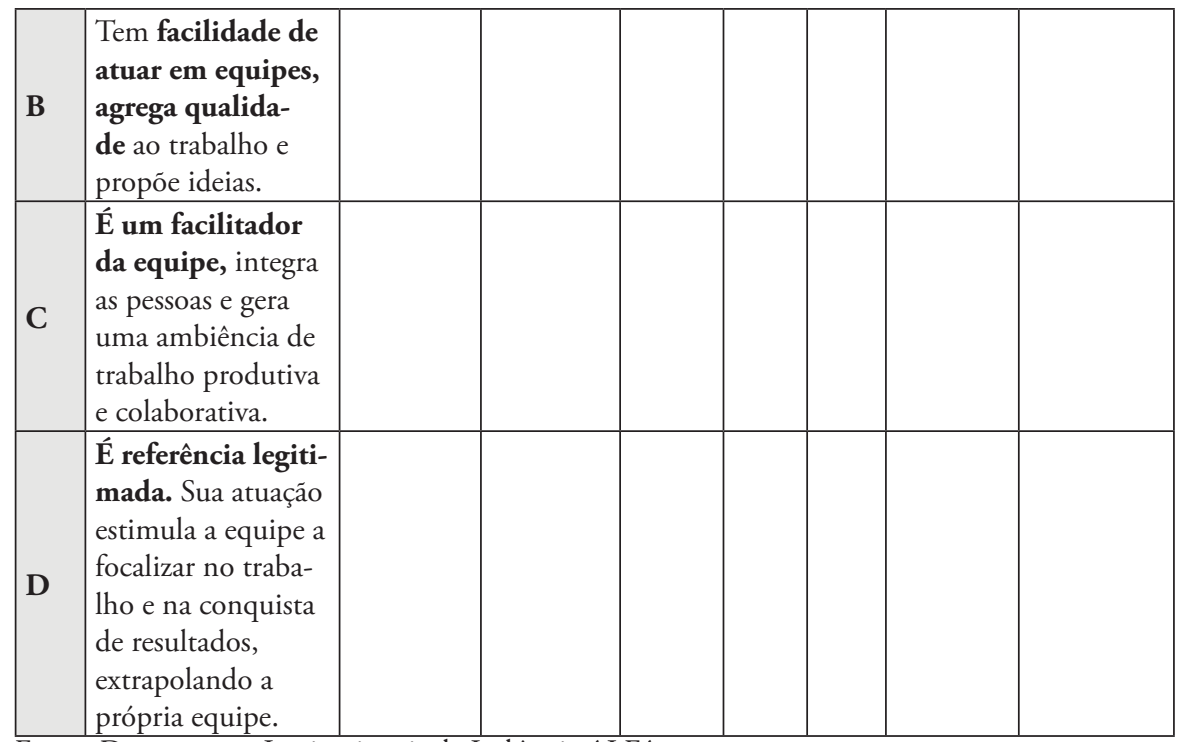

Fonte: Documentos Institucionais da Indústria ALFA.

No Quadro 2, em que se explicita a avaliação da escala de proficiência no âmbito dos processos e resultados, a orientação é no sentido de alcançar e superar metas definidas pela empresa. Nota-se aqui que a ideologia é a de superação das metas como garantia de qualidade e eficácia. As relaçóes de poder encontram-se definidas no processo de planejamento (e os resultados do processo), na orientação na execução da atividade, na autonomia para aprimorar os processos, na definiçẫo de metas desafiadoras e no comprometimento de esforços. As competências, novamente, não são as dos sujeitos do trabalho, mas aquelas que a empresa requer destes sujeitos, ou seja, são competências definidas pela Indústria ALFA (corporativas) para os sujeitos.

Subentende-se que os processos críticos, metas desafiadoras, esforços próprios e alheios descritos nesta competência individual exigem elevado grau de comprometimento e dedicaçáo do trabalhador, fazendo com que o mesmo não se acomode jamais, que esteja continuamente atento às mudanças, buscando, inovando, criando e superando metas desafiadoras. Porém, segundo Brito (2008), essa intensificação do processo de trabalho para ser eficazmente viabilizada, necessita não somente do consentimento, mas do comprometimento do trabalhador com seus resultados. "Desta forma, a situação do trabalhador 
torna-se cada vez mais complexa e contraditória e aponta para o aumento da tensão, exclusão e deterioração das relações que o homem realiza consigo próprio, com o corpo, com o outro e com a natureza" (BRITO, 2008, p. 216). Para o autor, a distância entre o que é cobrado e as reais condiçôes de trabalho - pressão por resultados, necessidade de melhoria contínua, competição interna para "fazer acontecer" - intensifica a exploração do trabalhador gerando um aumento da carga de trabalho, fazendo com que a vida do homem esteja intrinsecamente ligada à vida da organização, acarretando consequentemente o aparecimento de doenças ocupacionais (desgastes físico e mental), o medo da perda do emprego, o sofrimento psíquico negado, entre outras patologias.

Quadro 2-Escala de proficiência para as Competências Individuais Corporativas: orientaçáo para processos e resultados

\begin{tabular}{|c|c|c|c|c|c|c|c|c|}
\hline \multirow{2}{*}{\multicolumn{2}{|c|}{$\begin{array}{l}\text { Competências Individuais } \\
\text { Corporativas } \\
\text { Orientação para Processos e } \\
\text { Resultados }\end{array}$}} & \multicolumn{7}{|c|}{$\begin{array}{l}\text { ESCALA DE PROFICIÊNCIA } \\
\text { Avaliação }\end{array}$} \\
\hline & & \multirow{3}{*}{$\begin{array}{l}\text { Não me } \\
\text { sinto } \\
\text { apto a } \\
\text { avaliar }\end{array}$} & \multirow[b]{3}{*}{$\begin{array}{l}\text { Não } \\
\text { Demons- } \\
\text { trada }\end{array}$} & \multicolumn{3}{|c|}{$\begin{array}{l}\text { Em desenvolvi- } \\
\text { mento }\end{array}$} & \multirow[b]{2}{*}{$\begin{array}{l}\text { Apli- } \\
\text { cação } \\
\text { integral }\end{array}$} & \multirow[b]{2}{*}{$\begin{array}{l}\text { Supera } \\
\text { nível re- } \\
\text { querido }\end{array}$} \\
\hline \multirow{2}{*}{\multicolumn{2}{|c|}{$\begin{array}{l}\text { Capacidade de alcançar e } \\
\text { superar metas estabelecidas, } \\
\text { garantindo a qualidade } \\
\text { e eficácia dos processos. } \\
\text { Pressupóe planejamento, } \\
\text { acompanhamento e análise } \\
\text { dos processos que levam aos } \\
\text { resultados econômico-finan- } \\
\text { ceiros, sociais e ambientais. }\end{array}$}} & & & $\begin{array}{l}\text { Inicia- } \\
\text { ção }\end{array}$ & $\begin{array}{l}\text { Apli } \\
\text { inte } \\
\text { diár }\end{array}$ & ação & & \\
\hline & & & & 1 & 22 & 33 & 4 & 5 \\
\hline A & $\begin{array}{l}\text { Executa atividades } \\
\text { dos processos de sua } \\
\text { área sob orientaçáo, } \\
\text { considerando o poten- } \\
\text { cial impacto de suas } \\
\text { açóes nas áreas com as } \\
\text { quais interage. }\end{array}$ & & & & & & & \\
\hline B & $\begin{array}{l}\text { Executa atividades } \\
\text { dos processos de sua } \\
\text { área de forma autôno- } \\
\text { ma. Busca resultados } \\
\text { com iniciativa para } \\
\text { aprimorar processos, } \\
\text { procedimentos e } \\
\text { sistemas. }\end{array}$ & & & & & & & \\
\hline
\end{tabular}


No Quadro 3, as competências individuais são avaliadas quanto ao conhecimento compartilhado e à aprendizagem, incluindo a aprendizagem com as expectativas próprias e alheias e a "desaprendizagem", a qual se refere a uma forma de apagar o que não interessa ao trabalho que a Indústria ALFA requer. $\mathrm{O}$ discurso ideológico encontra-se expresso na busca de oportunidades de aprendizagem pelo sujeito do trabalho, em seu comportamento constante de aprender além do que a empresa requer, no compartilhamento de experiências adquiridas no trabalho e na promoção da capacidade de disseminar conhecimentos organizacionais e estratégicos de forma a transformar o conhecimento individual em organizacional. As relaçóes de poder encontramse dissimuladas, porém se evidenciam nas contradiçóes. Nota-se que a busca individual de oportunidades e por aprender para além do necessário, definidoras dos critérios de competências, entram em contradição com a concepçáo de que o conhecimento individual deve se transformar em organizacional. Portanto, o caráter do saber dos sujeitos do trabalho não se refere ao saber ontológico, mas ao saber útil para a ALFA.

A busca constante por oportunidades de aprendizagem pressupóe uma consciência de autodesenvolvimento e de transmissão consentida de conhecimento, onde o trabalhador deve estar continuamente buscando, criando e se autoeducando para então transferir, de forma estruturada, esse saber explícito. $\mathrm{O}$ produto do seu trabalho transforma-se em conhecimento corporativo, 
devidamente classificado e disponibilizado em bancos de "liçóes apreendidas" e de "boas práticas". Conforme análise de Brito (2008), ao mesmo tempo em que o trabalhador deve apreender e compartilhar o conhecimento organizacional e o raciocínio sistêmico, ele precisa também abrir mão de uma visão pessoal de mundo consolidada ao longo de sua existência, mudando continuamente seus quadros mentais, náo como um processo integral de desenvolvimento, mas negando sua própria identidade e referências para se adequar às necessidades do capital. Encontra-se aí outra contradiçáo. Se por um lado o trabalhador deve ser um "eterno aprendiz", estar em constante desenvolvimento, garantindo que sua aprendizagem individual seja transformada em organizacional, ao mesmo tempo este conhecimento só será válido e útil para a organização se tiver um caráter prático e um alinhamento aos objetivos e estratégias da organização.

Duas questôes podem ser formuladas: de que forma repensar o contexto organizacional e a relaçáo de trabalho sob a ótica da aprendizagem e do trabalho coletivo sendo que por detrás do discurso existe um trabalho individualizado e fragmentado? De que forma compreender as significaçôes do trabalho, o sentido de sua experiência, definir finalidades de suas açóes, permitindo que o sujeito contribua com a sociedade em que vive ao mesmo tempo em que não é estimulado a pensar criticamente, mas em reproduzir os discursos preestabelecidos? Constata-se que o sentido da educação ampla, crítica e libertadora, bases para a formação humana, é reduzida a um conjunto de conhecimentos práticos e instrumentais reiterando a subordinação do trabalhador a um sistema de crenças e de visão de mundo unilateral, legitimando os mecanismos de poder ao interesse do capital. 
Quadro 3 - Escala de proficiência para as Competências Individuais Corporativas: aprendizagem e compartilhamento do conhecimento

\begin{tabular}{|c|c|c|c|c|c|c|c|c|}
\hline \multirow{2}{*}{\multicolumn{2}{|c|}{$\begin{array}{l}\text { Competências Individuais } \\
\text { Corporativas } \\
\text { Aprendizagem e Comparti- } \\
\text { lhamento do conhecimento }\end{array}$}} & \multicolumn{7}{|c|}{$\begin{array}{l}\text { ESCALA DE PROFICIÊNCIA } \\
\text { Avaliação }\end{array}$} \\
\hline & & \multirow{3}{*}{$\begin{array}{l}\text { Náo me } \\
\text { sinto apto } \\
\text { a avaliar }\end{array}$} & \multirow{3}{*}{$\begin{array}{l}\text { Não De- } \\
\text { mons- } \\
\text { trada }\end{array}$} & \multicolumn{3}{|c|}{$\begin{array}{l}\text { Em desenvolvi- } \\
\text { mento }\end{array}$} & \multirow{3}{*}{$\begin{array}{l}\begin{array}{l}\text { Apli- } \\
\text { caçấo } \\
\text { integral }\end{array} \\
4\end{array}$} & \multirow{3}{*}{\begin{tabular}{|l}
$\begin{array}{l}\text { Supera } \\
\text { nível } \\
\text { requeri- } \\
\text { do }\end{array}$ \\
5
\end{tabular}} \\
\hline \multirow{2}{*}{\multicolumn{2}{|c|}{$\begin{array}{l}\text { Capacidade de buscar, apre- } \\
\text { ender, aplicar e disseminar } \\
\text { conhecimentos para o cres- } \\
\text { cimento pessoal e organiza- } \\
\text { cional. Inclui aprender com } \\
\text { as expectativas próprias e de } \\
\text { outros, bem com desapren- } \\
\text { der quando necessário. }\end{array}$}} & & & $\begin{array}{l}\text { Inicia- } \\
\text { ção }\end{array}$ & & $\begin{array}{l}\text { ação } \\
\text { ne- }\end{array}$ & & \\
\hline & & & & 1 & 2 & 3 & & \\
\hline $\mathbf{A}$ & $\begin{array}{l}\text { Busca oportuni- } \\
\text { dades de apren- } \\
\text { dizagem, aplica e } \\
\text { compartilha conhe- } \\
\text { cimentos quando } \\
\text { lhes sáo requeridos. }\end{array}$ & & & & & & & \\
\hline B & $\begin{array}{l}\text { Apresenta comporta- } \\
\text { mento de constante } \\
\text { busca do apren- } \\
\text { dizado além do } \\
\text { requerido, consegue } \\
\text { utilizar as compe- } \\
\text { tências adquiridas } \\
\text { em suas atividades e } \\
\text { compartilha conhe- } \\
\text { cimento de forma } \\
\text { consistente. }\end{array}$ & & & & & & & \\
\hline C & $\begin{array}{l}\text { Compartilha com } \\
\text { equipes conheci- } \\
\text { mentos e experi- } \\
\text { ências adquiridas, } \\
\text { sistematizando a } \\
\text { prática. }\end{array}$ & & & & & & & \\
\hline
\end{tabular}




$\left.\begin{array}{|l|l|l|l|l|l|}\hline \text { D } & \begin{array}{l}\text { Promove } \\ \text { em outros a } \\ \text { capacidade } \\ \text { de buscar, } \\ \text { apreender, aplicar } \\ \text { e disseminar } \\ \text { conhecimentos } \\ \text { organizacionais } \\ \text { estratégicos } \\ \text { e críticos, } \\ \text { garantindo que } \\ \text { a aprendizagem } \\ \text { individual seja } \\ \text { transformada em } \\ \text { organizacional. }\end{array}\end{array}\right)$

Fonte: Documentos Institucionais da Indústria ALFA.

Com o objetivo de reforçar e garantir a identidade da Indústria ALFA são definidos os níveis requeridos nas competências individuais para cada grupo de empregados, de acordo com sua posiçáo na empresa. Nem todas as competências individuais corporativas são obrigatórias para todos os empregados. Porém, em função da necessidade do trabalho ou desenvolvimento, quando uma competência individual corporativa opcional for aplicada, é utilizado o nível requerido pelo cargo ou função ocupada pelo empregado (poder e ideologia). O Quadro 4, adiante, mostra o perfil das competências associadas às funçôes.

A concepção de competência que orienta o perfil individual faz uma distinção de complexidade das funçôes, a qual é baseada em uma estrutura de poder. A complexidade não é tratada como conhecimento relativamente coerente, cujos componentes exigem diversas relaçôes de interdependência ou de subordinação e cuja aprendizagem possui um grau elevado de dificuldade cognitiva. Os aspectos complexos das tarefas não se encontram na hierarquia, mas nas relaçóes de interdependência, especialmente, no caso do processo de trabalho, aquelas que se referem aos relacionamentos interpessoais e intersubjetivos. Para a Indústria ALFA, a complexidade é associada à responsabilidade funcional. A ideologia que se manifesta neste perfil é a de que quanto mais dedicado e comprometido for o sujeito do trabalho para com a organizaçáo, mais complexa se torna a competência. 
Quadro 4 - Perfil de competências individuais associadas às funçóes e aos cargos da indústria ALFA

\begin{tabular}{|c|c|c|c|c|c|c|c|c|c|}
\hline \multirow[b]{2}{*}{$\begin{array}{l}\text { Compe- } \\
\text { tência }\end{array}$} & \multicolumn{6}{|l|}{ Funçóes } & \multicolumn{3}{|c|}{ Cargo } \\
\hline & $\begin{array}{l}\text { Gerente } \\
\text { Executivo }\end{array}$ & $\begin{array}{l}\text { Ge- } \\
\text { rente } \\
\text { Geral }\end{array}$ & $\begin{array}{l}\text { Geren- } \\
\text { te }\end{array}$ & $\begin{array}{l}\text { Coorde- } \\
\text { nador }\end{array}$ & $\begin{array}{l}\text { Super- } \\
\text { visor }\end{array}$ & $\begin{array}{l}\text { Espe- } \\
\text { cialista }\end{array}$ & $\begin{array}{l}\text { Sê- } \\
\text { nior }\end{array}$ & $\begin{array}{l}\text { Ple- } \\
\text { no }\end{array}$ & $\begin{array}{l}\mathrm{Ju}- \\
\text { nior }\end{array}$ \\
\hline $\begin{array}{l}\text { Trabalho } \\
\text { em equipe }\end{array}$ & D & D & D & D & C & $\mathrm{C}$ & C & B & A \\
\hline Iniciativa & D & D & D & C & $\mathrm{C}$ & $\mathrm{C}$ & C & B & A \\
\hline $\begin{array}{l}\text { Liderança } \\
\text { de pessoas }\end{array}$ & D & D & D & C & C & B & B & A & A \\
\hline $\begin{array}{l}\text { Atuaçáo } \\
\text { estratégica }\end{array}$ & D & D & C & B & B & C & B & A & A \\
\hline $\begin{array}{l}\text { Orien- } \\
\text { tação de } \\
\text { Processos } \\
\text { e resulta- } \\
\text { dos }\end{array}$ & D & D & D & C & C & C & C & B & A \\
\hline $\begin{array}{l}\text { Criati- } \\
\text { vidade e } \\
\text { Inovaçáo }\end{array}$ & D & D & C & C & B & D & B & A & A \\
\hline $\begin{array}{l}\text { Aprendi- } \\
\text { zagem e } \\
\text { Com- } \\
\text { partilha- } \\
\text { mento do } \\
\text { conheci- } \\
\text { mento }\end{array}$ & D & D & D & C & $\mathrm{C}$ & D & C & B & A \\
\hline $\begin{array}{l}\text { Foco no } \\
\text { cliente }\end{array}$ & D & D & D & $\mathrm{C}$ & $\mathrm{C}$ & $\mathrm{C}$ & C & B & A \\
\hline $\begin{array}{l}\text { Capaci- } \\
\text { dade de } \\
\text { decisão }\end{array}$ & D & C & C & B & B & B & B & A & A \\
\hline
\end{tabular}

Fonte: Documentos Institucionais da Indústria ALFA.

Obs.: Escala A, B, C e D, sendo que o nível A é o de menos complexidade e o D de maior complexidade.

\section{Competências Opcionais}

Os programas de gestão por competências, tal como o apresentado aqui, colocam em evidência a necessidade dos trabalhadores adaptarem-se aos objetivos organizacionais. Esses programas têm sido considerados inovadores 
na gestão do conhecimento, embora sejam expressōes reatualizadas de teorias oriundas da educação, das ciências sociais e da psicologia, como bem aponta Manfredi (1999, p. 2-3, grifo do autor):

Expressôes tais como "qualificação", "competência", "formação profissional" ocupam lugar de destaque nos discursos e documentos dos diferentes agentes e instituiçôes sociais. $\mathrm{O}$ uso desses conceitos polissêmicos, na grande maioria das vezes empregados como equivalentes e sinônimos, despertou nossa atenção, pois tanto na literatura como nos discursos aparecem como conceitos novos, atuais e nấo como reatualizaçóes [...]. A noção de qualificação está associada ao repertório teórico das ciências sociais, ao passo que o de competência está historicamente ancorado nos conceitos de capacidades e habilidades, constructos herdados das ciências humanas - da psicologia, educação e linguística.

Embora a noção de competência seja conhecida no Brasil desde os anos 1970 na área das ciências humanas e sociais, como insiste Manfredi (1999), a mesma aparece nos discursos organizacionais como consequência das necessidades impostas pelo desenvolvimento das forças produtivas. Para Hirata (1994), a noçẫo de competência decorre da necessidade das organizaçôes em avaliar e classificar novos conhecimentos e habilidades exigidas no processo de trabalho derivado da reorganização produtiva. Assim, a gestão por competências passa a ser uma necessidade das organizaçóes diante das transformaçóes do sistema de capital. Como mostra Faria (1992), a reorganização produtiva designada como produção flexível não pode ser considerada apenas como um processo de desenvolvimento de tecnologias físicas de base microeletrônica, mas igualmente de tecnologias de gestáo. Este modelo de desenvolvimento de competências para o trabalho encontra-se associado ao programa de avaliação de desempenho do trabalhador, segundo critérios de aptidáo, habilidade, conhecimento, capacidade de relacionamento interpessoal, entre outros. Tratase, assim, de um programa que expressa as relaçóes de poder nas organizaçôes tendo como suporte um discurso ideológico concatenado com as relaçóes sociais e de produção do sistema de capital. 


\section{Considerações finais}

O propósito desta pesquisa foi o de compreender de que forma a organização Indústria ALFA, mediante o uso de métodos, técnicas e processos embutidos em seu programa de Gestão por Competências, legitima a adesão, o envolvimento e a concentração do indivíduo na implantaçâo de sua missão e na busca de seus objetivos, ou seja, de seus interesses objetivos e subjetivos específicos. Para tanto, foi necessário revelar a lógica e o conteúdo do programa de Gestão por Competências a partir duas Categorias de Análise (Poder e Ideologia). A pesquisa indicou que o programa de Gestão por Competência da Indústria ALFA encontra-se alicerçado em uma dinâmica de relaçóes de poder e em uma ideologia materialmente ancorada e amplamente disseminada no âmbito da organização estudada.

Sendo a ideologia um sistema de ideias e de interpretação do mundo, a mesma se propóe a apresentar ao sujeito uma certeza e não uma verdade a ser descoberta. Para Enriquez (1997), as organizações precisam encontrar uma definição para formatar seu desenvolvimento e, desse modo, definem uma ideologia e propõem um ideal a ser seguido e atingido, colocando a si mesmas como objeto a ser admirado e cujos objetivos deverão ser alcançados, exigindo esforço e trabalho por parte dos seus membros. As organizações propiciam um ambiente de expectativas futuras através de promessas com vários sentidos e, por esta razão, apregoam a necessidade de entusiasmo e ao mesmo tempo de sacrifício dos seus empregados. As promessas fazem parte do discurso fascinante da organizaçáo e devem participar das construçóes imaginárias dos sujeitos, pois enquanto a organização oferta alguns elementos de seduçáo e promete outros, a mesma se constitui em um lugar seguro, em contraposiçáo às incertezas do mundo exterior.

Sendo portadora de ideais e fantasias, as organizaçôes, como sugerem Pagès et al. (1987), pretendem fornecer uma concepção de mundo conforme suas aspiraçôes e uma interpretação do real coerente com suas práticas sociais. Para ocupar seu lugar e realizar seus sonhos, o empregado é conduzido a compartilhar cada vez mais intensamente da ideologia da empresa, participando de tal forma do seu processo de institucionalização e reprodução, que sua submissão à mesma instaura uma relação na qual a organização não precisa coagi-lo e ameaçá-lo para estimulá-lo a produzir mais. À medida que se efetiva e se intensifica a integraçáo ideológica entre o sujeito e a organização, o resultado aparece no que esta mais investe: o aumento da produtividade. A adesão à 
ideologia do capital é uma forma de "sequestro da subjetividade" do empregado que a ela se entrega plenamente (FARIA, 2004). A ideologia corporativa do capital torna-se dogmática e o programa de gestão por competências se apresenta como um guia que se encontra à disposição, pois a ideologia é um nível de controle e uma base de poder.

Esta pesquisa reafirma as observaçóes de Pagès et al. (1987) de que a organização contemporânea através de um programa de competências exige dos trabalhadores que estes persigam o "ideal de perfeição", desenvolvendo processos de identificação e de introjeção dos valores organizacionais. Dessa forma, ao valorizar as competências, a organização induz o trabalhador a perseguir objetivos e regras que ela dita, mas que acabam por se tornar vitais para o seu próprio funcionamento psicológico, de maneira que este possa oferecer àquela uma extrema dedicação. O programa de Gestão por Competência da Indústria ALFA é um instrumento de organização e implantação de um comportamento padronizado, fundado na ideologia do talento e no poder hierárquico. Há um processo de indução de comportamento valorizado, comprometimento, adesão aos interesses da organização, estabelecendo condiçôes de desempenho capazes de manter os sujeitos do trabalho envolvidos e empenhados na disseminaçáo dos valores e interesses objetivos e subjetivos específicos da Indústria ALFA.

\section{Notas}

${ }^{1} \mathrm{O}$ nome da Indústria será mantido em sigilo por exigência da mesma.

${ }^{2}$ De fato, é uma simplificação atribuir à teoria piagetiana a responsabilidade pelos programas de desenvolvimento e gestáo do conhecimento aplicados nas organizaçóes contemporâneas. Entender a proposta de Piaget ajuda a entender a lógica destes programas, mas não autoriza sua responsabilização.

\section{REFERÊNCIAS}

BARDIN, Laurence. Análise de Conteúdo. Lisboa: Ediçōes 70, 2002.

BATISTA, Eraldo Leme; CLARK, Jorge Ulson. A Ideologia do Trabalho e da Educação Profissional no contexto das reformas neoliberais. Revista Rede de Estudos do Trabalho. Sáo Paulo, ano 3, n. 5, 2009. 
BATTRO, Antonio M. Dicionário terminológico de Jean Piaget. São Paulo: Pioneira, 1978.

BRITO, Lydia Maria Pinto. Gestão de competências, gestão do conhecimento e organizaçóes de aprendizagem: instrumentos de apropriação pelo capital do saber do trabalhador. Cadernos de Educação, Pelotas, RS, n. 31, p. 203 - 225, jul./dez. 2008.

BOAM, Rosemary; SPARROW, Paul. Designing and achieving competency: a competency-based approach to developing people and organizations. New York: McGraw-Hill, 1992.

BUSS, David M. Evolucionary psychology: the new Science of the mind. Boston: Allyn and Bacon, 1999.

CASTORIADIS, Cornelius. A instituição imaginária da sociedade. Rio de Janeiro: Paz e Terra, 1982.

CENTRE for Contemporary Cultural Studies. Da ideologia. Rio de Janeiro: Zahar, 1980.

DAMÁSIO, António. The feeling of what happens: body and emotions in the making of the consciousness. New York: Harcourt Brace, 1999.

DEJOURS, Chistophe. A banalização da injustiça social. 4. ed. Rio de Janeiro: Editora FGV, 2001.

ENRIQUEZ, Eugène. Organização em análise. Petrópolis, RJ: Vozes, 1997.

FARIA, José Henrique de. Tecnologia e processo de trabalho. Curitiba: Editora da UFPR, 1992.

FARIA, José Henrique de. Economia politica do poder. Curitiba: Juruá, 2004. 3v.

FARIA, José Henrique de. Tecnologia, processo e organização do trabalho. São Paulo. RAUSP; FEA-USP, 2007.

FARIA, José Henrique; LEAL, Anne Pinheiro, A gestão por competências no quadro da hegemonia, 2005. In: FARIA, José Henrique (Org.). Análise crítica das teorias e práticas organizacionais. São Paulo: Atlas, 2007. p. 142-166.

FLEURY, Maria Tereza Leme; FLEURY, Afonso. Construindo o conceito de competência. Revista de Administração Contemporânea, Curitibav. 5, n. especial, p. 183-196, 2001. 
FRANCO, Maria Laura Puglisi Barbosa. Representaçóes Sociais, Ideologia e Desenvolvimento da Consciência. Cadernos de Pesquisa, São Paulo, v. 34, n. 121, p. 169-186, jan./abr. 2004.

FRANCO, Maria Laura Puglisi Barbosa. Análise do conteúdo. 2. ed. Brasília: Liber Livros, 2007.

GAULEJAC, Vincent. Gestão como doença social. Aparecida, SP: Ideias \& Letras, 2007.

HIRATA, Helena. Da polarização das qualificaçôes ao modelo de competência. In: FERRETTI, Celso J. et al. Novas tecnologias, trabalho e educação: um debate multidisciplinar. Petrópolis, RJ: Vozes, 1994. p. 124-138.

MANFREDI, Silvia Maria. Trabalho, qualificação e competência profissional: das dimensões conceituais e políticas. Educação \& Sociedade, Campinas, SP, v. 19, n. 64, 1999.

MARX, Karl; ENGELS, Friedrich. A ideologia alemã: crítica da mais recente filosofia alemã em seus representantes Feuerbach, B. Bauer e Stirner, e do socialismo alemão em seus diferentes profetas $(1845$ - 1846). São Paulo: Boitempo, 2007.

McCLELLAND, Douglas C. Education for competence. In: HECKHAUSEN, H.; EDELSTEIN, W. (Ed.). Proceedings of the 1971 FOLEB Conference. Berlin: Institut fiir Bildungsforschung in der MaxPlanck-Gesellschaft, 1971.

McCLELLAND, Douglas C. Testing for competence rather than intelligence. The American Psychologist, Washington, n. 28, n. 1, p. 1-14, jan. 1973.

MÉSZÁROS, István. Para além do capital. São Paulo: Boitempo, 2002.

MÉSZÁROS, István. O poder da ideologia. São Paulo: Boitempo, 2004.

MIRABILE, Richard J. Everything you wanted to know about competency modeling. Training and Development, v. 51, n. 8, p. 73-77, aug. 1997.

PAGÈS, Max et al. O poder das organizaçôes. São Paulo: Atlas, 1987.

PIAGET, Jean. Problemas da psicologia genética. Rio de Janeiro: Forense, 1973. 
PIAGET, Jean. O nascimento da inteligência na criança. Rio de janeiro: Zahar, 1975.

PIAGET, Jean. A equilibração das estruturas cognitivas: problema central do desenvolvimento. Rio de Janeiro: Zahar, 1976.

PRAHALAD, C. K.; HAMEL, Gari. The core competence of the corporation. Harvard Business Review, Cambridge, v. 74, n. 6, nov./dec. 1996.

RICOUER, Paul. Interpretação e ideologia. São Paulo: Francisco Alves, 1990.

SIQUEIRA, Marcus Vinicius Soares. O discurso organizacional em recursos humanos e a subjetividade do individuo: uma análise crítica. Tese (Doutorado em Administração de Empresas)Escola de Administração de Empresas de São Paulo da Fundação Getúlio Vargas, São Paulo, 2004.

WHITE, R. W. Motivation reconsidered: the concept of competence. Psychological Review, Washington, n. 66, p. 297-333, 1959.

YIN, Robert K. Estudo de caso: planejamento e método. Porto Alegre: Bookman, 2005.

ZARIFIAN, Philippe. Objetivo competência. São Paulo: Atlas, 2001. 


\section{Poder e Ideología: el modelo corporativo de gestión por competencias en una industria multinacional}

\section{Resumen}

Las organizaciones están atravesadas por contradictorias y complejas relaciones provocadas por los mecanismos de poder, ideología y control. El interés de este artículo es analizar cómo se manifiestan estas relaciones en el discurso de la gestión por competencia, a través del análisis crítico del contenido acerca del modelo corporativo en una industria multinacional, llamada Industria Alfa. El estudio se desarrolla a partir de dos categorías de análisis: el poder y la ideología. Las fuentes de datos empíricos son los documentos que definen y guían a los procedimientos de gestión basada en competencias en la Industria Alfa. La técnica de recolección de datos y análisis será el Análisis de Contenido según la propuesta de Bardin y Franco. El enfoque que orienta el problema de la investigación será alrededor del discurso del sujeto colectivo y su relación establecida con el conjunto de reglas y comportamientos que son impuestos ideológicamente y que se materializan a través de la sumisión, la alienación y la servidumbre voluntaria en las organizaciones. La base conceptual de esta investigación tendrá en cuenta una concepción teórica crítica en relación a las formas de poder y de control en organizaciones específicas.

Palabras claves: Gestión por competencias. Relaciones de trabajo. Ideología y poder.

\section{Power and ideology: the corporate model of management skills in a multinational industry}

\section{Abstract}

The organizations are permeated by complex and contradictory relations triggered by mechanisms of power, ideology and control. The goal of this study is to analyze how these relations are manifested in the discourse of Management by Competence, through critical analysis of the corporative model deployed in a Multinational Industry, here named ALPHA Industry, considering two categories of analysis: power and ideology. The empirical data sources are the institutional documents of ALFA Industry that define and guide the Competency based management procedures. The technique of data collection and analysis is the analysis of content according to proposal of Bardin and Franco. The approach that guides the search problem will be around the collective subject and its relation with the set of rules and behaviors required for ideological organization, which materializes through the submission, the alienation and the voluntary servitude in organizations. The conceptual base that will support this investigation is characterized as a theoretical design critique of forms of power and control in organizations.

Keywords: Management skills. Working relationships. Power and ideology. 


\section{Cinthia Leticia Ramos}

E-mail: cinthialeticia.ramos@gmail.com

\section{José Henrique de Faria}

E-mail: jhfaria@gmail.com

Enviado em: 2/2/2013

Versão final: $14 / 3 / 2014$

Aprovado em: 16/3/2014 